\title{
ATRIAL FLUTTER WITH COMPLETE HEART BLOCK
}

\author{
BY \\ C. P. NEWCOMBE, D. DE SOUZA, AND J. R. H. TOWERS \\ From the General Infirmary at Leeds \\ Received, February 8, 1960
}

The association of atrial flutter and complete heart block is very uncommon. Amongst 168 cases of atrial flutter described by Willius (1927) only one had complete heart block, and in a review of 20,000 electrocardiograms Di Gregorio and Crawford (1939) found the combined dysrhythmia only twice. Campbell (1944) in his analysis of 64 cases of heart block does not mention the association, and of the large series of 251 patients with complete heart block discussed by Penton et al. (1956) four had atrial flutter.

In a recent review, Korst and Wasserburger (1954) mentioned 72 cases of whom 57 were men: the ages ranged from 14 to 84 years and the great majority occurred in the sixth and later decades. We have found reports of only 14 cases under fifty, 9 men and 5 women, and of these 10 showed evidence of organic heart disease. The four cases forming the subject of this report are men under fifty years of age, and the third and fourth have no evidence of organic heart disease.

Case 1 first came under observation in 1951 at the age of 41 complaining of stabbing pain in the right side of the chest, and had been aware of the slow pulse rate for two years. The past and family histories gave nothing unusual. The chest X-ray showed a normal heart shadow and the cardiogram revealed atrial sinus rhythm, complete heart block, and normal QRS-T complexes.

In 1957 he was admitted to hospital with severe vertigo, vomiting, and paraesthesiæ down the left half of the body due to thrombosis of the right posterior inferior cerebellar artery. He also described central chest pain on effort, rapidly relieved by rest, and present for the previous five years. The blood pressure was $160 / 90$, the pulse rate was 40 a minute, and the heart was clinically normal.

Cardiography (Fig. 1A) showed that the atrial rate was 340 a minute and the ventricular rate 35 a minute with complete dissociation, and there was also right bundle-branch block. This appearance remained unaltered in subsequent tracings.

Case 2 presented in March, 1950, at the age of 44; six months previously he had experienced sudden tightness in the chest associated with sub-sternal pain, and from that time he had noticed increasing dyspnœa and sub-sternal discomfort on effort. He was found to have a pulse rate of 48 and his cardiogram (Fig. 1B) showed an atrial rate of 250 a minute, a ventricular rate of 54 and right bundle-branch block. Serial records have shown a similar rhythm with some variation in atrial and ventricular rates, and apart from one brief period of atrial sinus rhythm the flutter has now been present for eight years. The QRS-T complexes have varied considerably, associated with episodes of prolonged sub-sternal pain and some illustrative tracings are shown in Fig. 2.

Congestive heart failure developed in 1954 and has since recurred several times, paracentesis abdominis being required in 1954, 1957, and 1958. Since failure first occurred the predominant symptoms have been dyspnœa and lassitude and there has been little pain. Stokes-Adams attacks have been present in recent months only. Serial radiographs have shown progressive cardiac enlargement (cardio-thoracic ratio, $50 \%$ in $1950,57 \%$ in $1953,65 \%$ in 1955 , and $69 \%$ in 1958 ).

Case 3, a moulder, aged 32, was seen in 1955 having had transient dizziness on two occasions during the previous eighteen months, each attack lasting for a few minutes. There was no significant past or family history. The blood pressure was 140/80, he had a regular pulse rate of 40 a minute, the heart was not enlarged, the heart sounds were normal, and there was a soft systolic ejection murmur in the third left intercostal space attributed to the bradycardia. 


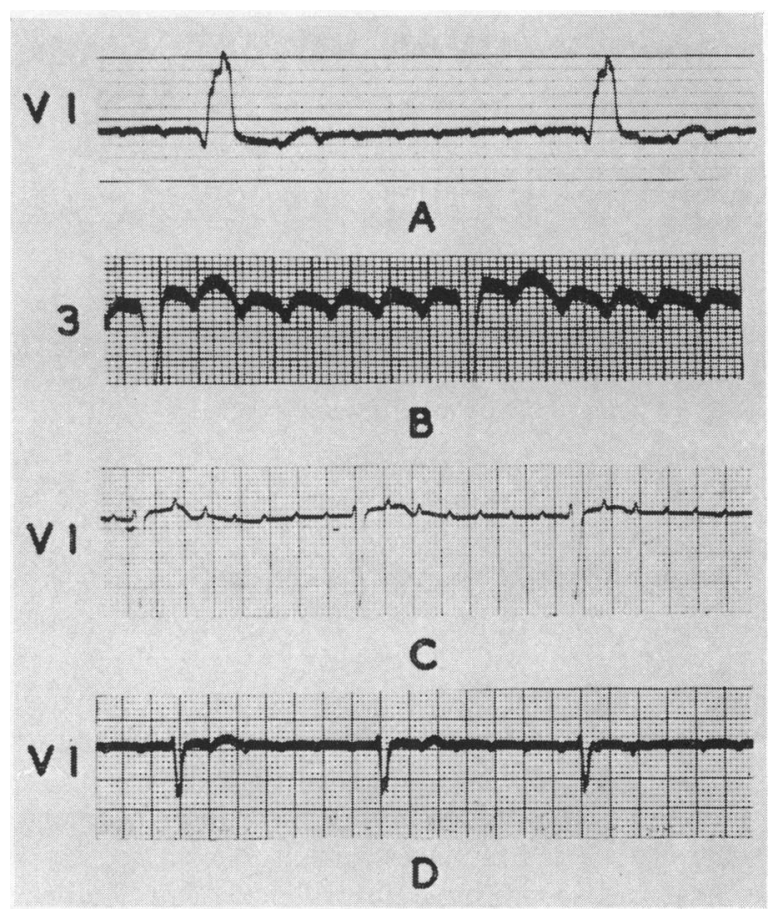

FIG. 1.-Single electrocardiograph leads from each case to demonstrate the arrhythmia.

(A) Case 1. (B) Case 2. (C) Case 3. (D) Case 4.

The chest X-ray was normal. He showed an atrial rate of 280 and a ventricular rate of 36; the QRS-T complexes were normal (Fig. 1C). Attempts to restore sinus rhythm with quinidine sulphate, 10 grains, two-hourly for three doses, and procaine amide, $3.5 \mathrm{~g}$. in twelve hours, were unsuccessful. No further dizziness has occurred since he was given half a grain of ephedrine, q.i.d., but no objective change has been produced.

During five years observation the atrial rate has been constantly 280 a minute and the ventricular rate has varied between 36 and 52 beats a minute. He is symptom free and is working.

Case 4, a tailor's cutter, aged 49, was noted to have bradycardia when examined before herniorrhaphy. He had no symptoms suggesting cardiac disease. Two brothers had died suddenly aged 40 and 41 years, but the remainder of the family were healthy. A sister was seen and was normal both clinically and cardiographically.

His blood pressure was 140/70 and apart from bradycardia there was no clinical abnormality. Radiologically the heart was normal. He had an atrial rate of 250 , a ventricular rate of 42 , and normal QRS-T complexes (Fig. 1D). This patient also is free from all symptoms and working three years later, the cardiogram being unchanged.

\section{Discussion}

The combination of atrial flutter with complete heart block may be found in digitalis intoxication, in association with organic heart disease, or as an isolated finding.

The association with digitalis intoxication is not very rare and may be due either to the production of complete heart block in a case of atrial flutter or to the initiation of atrial flutter in preexisting complete heart block. As pointed out by Lown et al. (1953) potassium depletion accentuates any manifestation of digitalis intoxication, and under such circumstances potassium salts may abolish the arrhythmia. In the spontaneous forms potassium is ineffective and other drugs seldom restore normal rhythm. Atrial sinus rhythm is sometimes produced by digitalis or quinidine 
20. 3. 50 14. 4. 50 . 13.10.5Q 14.12.51. 18.3.55. 16.1.57.

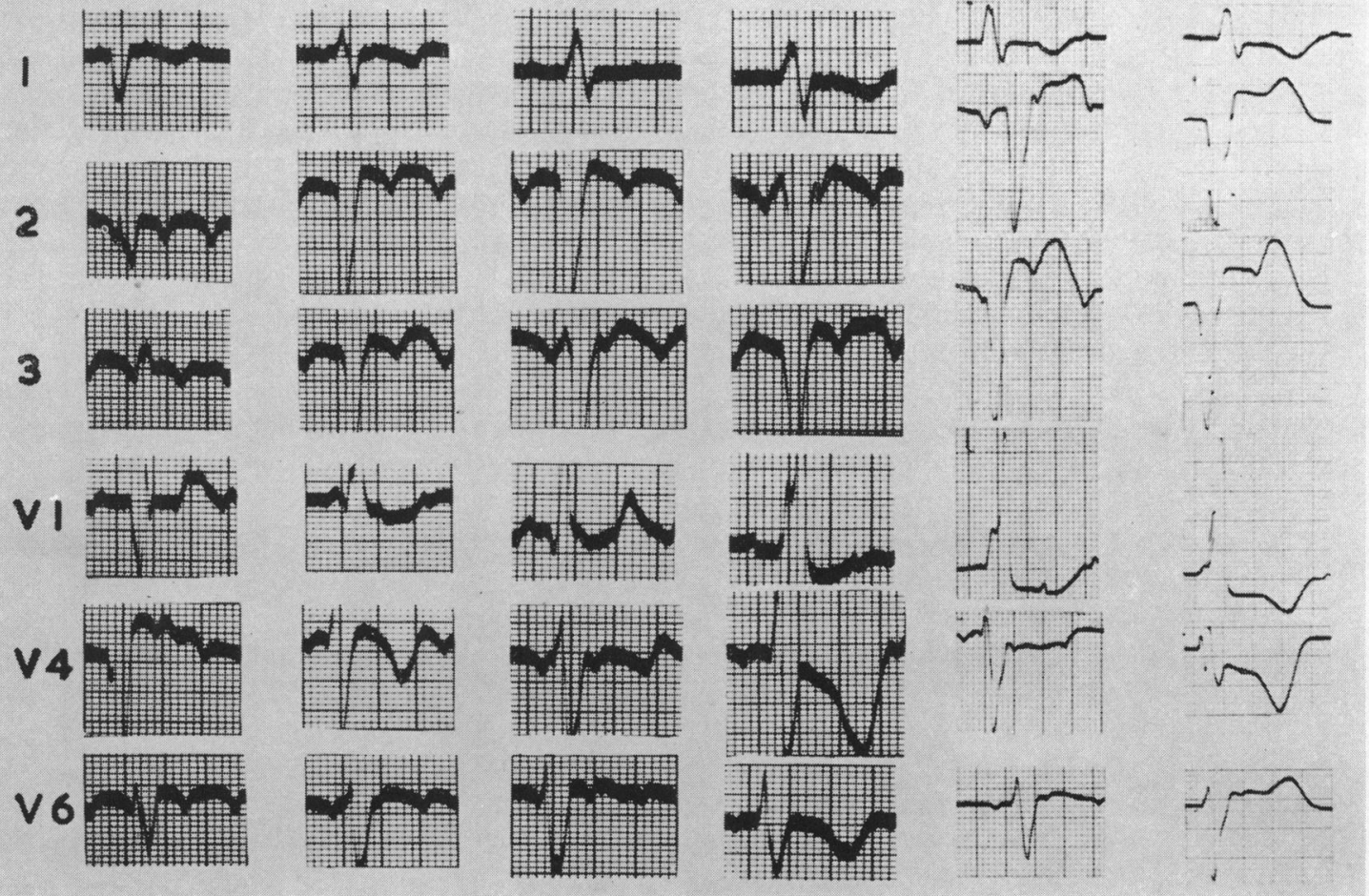

FIG. 2.-Serial electrocardiographs from Case 2.

but the heart block almost invariably persists. None of our cases had received digitalis before the arrhythmia was established.

Korst and Wasserburger found that coronary disease had been diagnosed in 42 of 72 cases, 25 of these having hypertension also. We have studied the original reports of many of these cases, and although many of the cardiograms showed abnormalities of the $T$ wave and often bundle-branch block, pathological $\mathrm{Q}$ waves were very infrequent and in only two could the evidence of infarction be accepted with confidence. The clinical histories in most were quite short with dyspnœa predominant and pain relatively inconspicuous, and in a number dyspnœa progressed rapidly to congestive heart failure. Unfortunately, necropsies were reported very infrequently but of particular interest was one described by Di Gregorio and Crawford (1939), a man of 62 who developed sudden cardiac pain regarded as infarctive followed by progressive cardiac failure with gross cardiac enlargement. At necropsy the heart weighed 800 g., the coronary arteries were patent, and the only abnormality was a small amount of fibrosis in relation to the bundle of His: the histology of the myocardium was not described. Other necropsy findings were described by Gray and Greenfield (1944) who found advanced myofibrosis of the left ventricle in a man of 60, by Thorborg (1943) who found mitral and aortic valve disease in a woman of 65, and by Jourdonais and Mosenthal (1937) where two of the cases reviewed had lesions of the bundle of His, one having also an unspecified septal defect.

Of our group, Cases 1 and 2 are regarded as having organic heart disease. Case 1 almost certainly has coronary artery disease; during the six-year interval between his first and second presentation he has developed classical anginal symptoms, right bundle-branch block, and atrial 
flutter in addition to the pre-existing heart block and has also had a cerebral thrombosis. In Case 2 the problem is more difficult and the course of his illness has closely resembled that of the cases described by Di Gregorio and Crawford to which reference has already been made, by Miller and Perelman (1946), and by Brandman et al. (1950, Case 5). There has been steadily progressive myocardial disease and repeated episodes in which the $T$ waves have changed, often associated with chest pain, but no pathological $Q$ waves have appeared. For the last four years, since congestive failure first developed there has been little pain. The enlargement has been generalized and there is no localized loss of pulsation or evidence of ventricular aneurysm on fluoroscopy. In spite of these atypical features coronary artery disease is the probable explanation for his illness but there is a possibility that he has a cardiomyopathy. Such a condition could well have been present in some of the 14 cases under fifty in whom congestive heart failure was found without adequate explanation (De Mourra, 1949; Smith and Smith, 1950; and Rattigan et al., 1952).

We have no reason to suspect intrinsic heart disease in our Cases 3 and 4 except for the family history in the latter. They suffer no disability and lead active lives. Prinzmetal et al. (1952) have shown that atrial flutter most commonly arises low in the atrium and the dual arrhythmia might be explained by a circumscribed abnormality in the region of the A-V node.

Few patients have been followed up for long periods but Cases 6 and 7 of Hanssen (1949) were followed for eleven years and developed only mild symptoms. Parkinson and Bedford (1927, Case 37) record a man of 33 in whom the flutter was abolished by digitalis: later he developed persistent atrial fibrillation but was symptom-free seven years later.

Case 3 has already been under observation for five years and has shown no deterioration, but it is possible that longer observation may reveal evidence of progressive disease.

\section{SUMMARY}

Four cases presenting the rare combination of atrial flutter with complete heart block are described, all being under 50. In two there is evidence of associated myocardial disease and in two the arrhythmia appears to be the only abnormality.

Reports of only 14 previous cases under the age of 50 have been found and reasons are given for suspecting that some cases attributed to coronary disease may be due to primary cardiomyopathies.

In a small number of cases the arrhythmia appears to be the only abnormality, but the late prognosis of these cases is unknown.

We thank Dr. R. N. Tattersall and Dr. O. H. Maxwell Telling for permission to study and report Cases 1 and 2 respectively.

\section{REFERENCES}

Brandman, O., Messinger, W. J., Redisch, W., and Zeltmacher, K. (1950). Ann. intern. Med., 33, 659.

Campbell, M. (1944). Brit. Heart J., 6, 69.

De Mourra, J. P. P. (1946). Amer. Heart J., 32, 794.

Di Gregorio, N. J., and Crawford, J. H. (1939). Amer. Heart J., 17, 114.

Gray, I., and Greenfield, I. (1944). Ann. intern. Med., 20, 125.

Hanssen, P. (1949). Acta. med. scand., 136, 112.

Jourdonais, L. F., and Mosenthal, H. O. (1937). Amer. Heart J., 14, 735.

Korst, D. R., and Wasserburger, R. H. (1954). Amer. Heart. J., 48, 383.

Lown, B., Wyatt, N. F., Crocker, A. T., Goodale, W. T., and Levine, S. A. (1953). Amer. Heart J., $45,589$.

Miller, R., and Perelman, J. S. (1946). Amer. Heart J., 31, 501.

Parkinson, J., and Bedford, D. E. (1927). Quart. J. Med., 21, 21.

Penton, G. B., Miller, H., and Levine, S. A. (1956). Circulation, 13, 801.

Prinzmetal, M., Corday, E., Brill, I. C., Oblath, R. W., and Kruger H. E. (1952. The Auricular Arrhythmias. C. C. Thomas, Springfield, Illinois, p. 188.

Rattigan, J. P., Byrnes, W. W., Kraus, H., and Sise, H. S. (1952). New Engl. J. Med., $246,130$.

Smith, A. L. Jr., and Smith A. L., (1950). Amer. Heart J., 40, 142.

Thorborg, N. (1943). Acta med. scand., 114, 507.

Willius, F. A. (1927). Amer. Heart J., 2, 449. 